\title{
Determinants of General Chemistry Success of Engineering Students in PLTL and Traditional Classroom: State Anxiety and Test Anxiety
}

\author{
Ece N. Eren-Sisman ${ }^{1 *}$, Ceyhan Cigdemoglu ${ }^{2}$ and Ömer Geban ${ }^{1}$ \\ ${ }^{1}$ Department of Mathematics and Science Education, Middle East Technical University, 06800, \\ Ankara, Turkey \\ ${ }^{2}$ Department of Educational Sciences, At1lım University, 06830, Ankara, Turkey
}

\begin{abstract}
The purpose is to find out whether state and test anxiety can predict general chemistry grade in peer-led team learning group (PLTL) and non-PLTL groups and to explore their predictability of the grade after controlling the influence of trait anxiety. The sample consisted of a total 128 freshman engineering students attending general chemistry in a private university. STAI and RTT instruments and exams were used to generate data which were analyzed by using standard and hierarchical multiple regression. The findings revealed that in both groups the combination of predictors is significantly related to general chemistry grade, having the strongest unique contribution of test anxiety; however, it was only statistically significant for PLTL group. After controlling the effect of trait anxiety, test anxiety still makes a unique significant contribution for PLTL group. Accordingly, test anxiety can be used to predict the general chemistry grade of PLTL students.
\end{abstract}

\section{Introduction}

\subsection{Anxiety experiences}

Anxiety as an element of the affective domain of learning is a significant factor since they can influence students' understanding of science [1]. Anxiety is also classified as trait anxiety and state anxiety by Spielberger et al. [2], who define the state anxiety as an interpretation of a particularly stressful situation at a particular time while trait anxiety was defined as a permanent personality characteristic or a general feeling of anxiety. Some studies confirmed that state and trait anxiety can be a significant predictor of academic achievement, in others, there are findings contrary to this view. Besides, test anxiety refers to the experience of the high level of anxiety elicited by testing in academic settings [3]. They also stressed that it is an important issue that can associate with the academic performance of college students.

\footnotetext{
* Corresponding author: neren@metu.edu.tr
} 


\subsection{Peer-led team learning}

Peer-led team learning (PLTL) model was first introduced in general chemistry classes as at The City College of New York (CCNY) for a systemic initiative in chemistry in the early 1990s and was disseminated by many institutions nationwide across all STEM disciplines in the US [4].

In PLTL model, lectures are first introduced by the course instructors and then these lectures are supplemented with weekly PLTL workshops in which a successful undergraduate student (peer leader) guides a group of 6-8 students for one or two hours per week to solve problems developed by the course instructor [4]. Peer leaders also meet with the instructor to discuss the topics and solve the problems correlated with the course content by providing conceptual understanding and critical thinking. Unlike a teacher in the traditional sense of lecturing or a teaching assistant in demonstrating how to solve the problem, "peer leader" is a facilitator or guide who earned at least a B in the same course in the previous years.

All conditions regarding six critical components of the model, namely involvement of faculty members, integration of the workshops to the lecture, good leader selection and training, appropriate materials, appropriate organizational arrangements and administrative supports should be met for implementation and dissemination of the model since it was advised to be implemented properly so as to achieve highly remarkable results [4].

\subsection{Purpose and research questions}

This study aimed at finding out whether state and test anxiety can predict general chemistry grade of engineering students in PLTL and non-PLTL groups and which anxiety is the best predictor of the success. Additionally, we aimed at exploring whether they are still able to predict the general chemistry grade in the case of controlling the possible effect of trait anxiety.

As a result, the research questions were established as follows:

1. How well do the two measures of anxiety (state and test anxiety scores) predict general chemistry grade of PLTL and non-PLTL groups? How much variance in general chemistry grade can be explained by scores on two measures for PLTL and non-PLTL groups?

2. Which is the best predictor of general chemistry grade for PLTL and non-PLTL groups: state anxiety, or test anxiety?

3. If we control the possible effect of trait anxiety, is this set of variables still able to predict a significant amount of the variance in general chemistry grade?

\section{Methods}

This paper employed the predictive study type of the correlational research. If there is a relationship with sufficient magnitude between two variables, one variable can be used to predict the other variable [5]. Therefore, in the current study state anxiety and test anxiety were used to make the prediction (predictor variables) about the general chemistry grade (criterion variable) of students in PLTL and non-PLTL groups.

\subsection{Context and sample of the study}

The sample consisted of two groups of students who were total 128 freshman engineering students in Atılım University in Turkey. Two intact sections of General Chemistry course taught by the same instructor were selected. 68 students in one section attended PLTL while 
60 students in other section of the course participated in the traditional instruction group. In the PLTL group, in two-thirds of the class time instructor explained the concepts as in the traditional classroom and in the remaining time, students solve a set of structured problems under the guidance of a peer leader who has completed the course successfully and trained in accordance with the framework of PLTL. Throughout the semester students attended six workshops twice a week and in addition to the workshops, team leaders participated in eight training sessions. In the traditional group, the same instructor described the topics and solve problems simultaneously in whole lecture time. At the beginning of the semester, all students informed about the study and signed the voluntary participation form.

\subsection{Data collection tools}

\subsubsection{State-trait anxiety inventory (STAI)}

It was used to measure two distinct anxiety concepts: state and trait anxiety. The inventory consists of 2 subscales: state anxiety scale and trait anxiety scale. It has a total of 40 items: Items 1 - 20 measure situational or state anxiety (STAI-S) and items 21 - 40 measure trait anxiety (STAI-T). After reversing scores for positively-worded items, a total score of a student get from each scale was minimum 20 and maximum 80 . The high score shows a high level of anxiety.

\subsubsection{Reaction to test (RTT)}

It was used to measure the presence of test anxiety. It consisted of 20-item. Total score of a student get from this inventory was minimum 20 and maximum 80 . High scores show a high level of test anxiety.

\subsubsection{General chemistry (GC) grade}

It was calculated from the raw score in points required from two midterms, one final exam and a laboratory work. All exams were scored out of 100 so maximum score that a student can obtain from these exams was 100 and the minimum score was 0 . Their contribution rates were $25 \%$ for each midterm, $35 \%$ for the final exam and $15 \%$ for laboratory work of the total grade

\subsection{Data analysis}

STAI and RTT instruments were used to generate data about trait and state anxiety and test anxiety respectively while students' general chemistry grade was calculated from the exams and a laboratory work. These data were analyzed by using standard multiple regression to address first and second research questions and were analyzed by hierarchical multiple regression to address third research question via IBM SPSS (Statistical Package for the Social Sciences) Statistics 24.0 program for Windows. Before conducting a regression analysis, all assumptions were satisfied.

\section{Results and discussion}

\subsection{Correlational results}

According to Table 1 below, for PLTL group students there was a statistically significant association between test anxiety and general chemistry (GC) grade while for non-PLTL 
group students there was a statistically significant association between trait anxiety, state anxiety, test anxiety and general chemistry (GC) grade. Thus, they could be used as predictor variables. Additionally, all anxiety-related variables showed high correlation with each other. Since trait anxiety as a permanent personality characteristic is difficult to change easily by using teaching methods or strategy, it was used as a covariate in the study.

Table 1. Correlations among all variables

\begin{tabular}{|c|c|c|c|c|c|c|c|c|}
\hline & \multicolumn{4}{|c|}{ PLTL group } & \multicolumn{3}{c|}{ NON-PLTL group } \\
\hline Variable & $\begin{array}{c}\text { GC } \\
\text { grade }\end{array}$ & $\begin{array}{c}\text { Trait } \\
\text { anxiety }\end{array}$ & $\begin{array}{c}\text { State } \\
\text { anxiety }\end{array}$ & $\begin{array}{c}\text { Test } \\
\text { anxiety }\end{array}$ & $\begin{array}{c}\text { GC } \\
\text { grade }\end{array}$ & $\begin{array}{c}\text { Trait } \\
\text { anxiety }\end{array}$ & $\begin{array}{c}\text { State } \\
\text { anxiety }\end{array}$ & $\begin{array}{c}\text { Test } \\
\text { anxiety }\end{array}$ \\
\hline $\begin{array}{c}\text { GC } \\
\text { grade }\end{array}$ & - & -.159 & -.168 & $-.315^{* *}$ & - & $-.270^{*}$ & $-.314^{*}$ & $-.355^{* *}$ \\
\hline $\begin{array}{c}\text { Trait } \\
\text { anxiety }\end{array}$ & -.159 & - & $.769^{* *}$ & $.609^{* *}$ & $-.270^{*}$ & - & $-762^{* *}$ & $.706^{* *}$ \\
\hline $\begin{array}{c}\text { State } \\
\text { anxiety }\end{array}$ & -.168 & $.769^{* *}$ & - & $.492^{* *}$ & $-.314^{*}$ & $-762^{* *}$ & - & $.572^{* *}$ \\
\hline $\begin{array}{c}\text { Test } \\
\text { anxiety }\end{array}$ & $-.315^{* *}$ & $.609^{* *}$ & $.492^{* *}$ & - & - & $.706^{* *}$ & $.572^{* *}$ & - \\
\hline
\end{tabular}

* Correlations significant at the 0.05 level, $\mathrm{p}<.05 * *$ Correlations significant at the 0.01 level, $\mathrm{p}<.01$

\subsection{Addressing the first research question: The prediction of GC grade from the combination of two variables}

In order to answer the questions of "How well do the two measures of anxiety (state and test anxiety scores) predict general chemistry grade of PLTL and non-PLTL groups?" and "How much variance in general chemistry grade can be explained by scores on two measures for PLTL and non-PLTL groups?" the Table 2 and 3 were analyzed. The coefficients of multiple regression which were .315 for PLTL and .380 for a non-PLTL group indicates a medium level correlation between the combination of predictor variables (state and test anxiety) and a criterion variable (general chemistry grade). The $\mathrm{R}$ square value (coefficient of determination) in Table 2 tell us how much of the variance in total grade is explained by the model (which includes the state and test anxiety). In the study, this value was .099 for PLTL group students and .144 for non-PLTL group students which referred that our model explained $9.9 \%$ and $14.4 \%$ of the variance in general chemistry grade for PLTL and non-PLTL group respectively. Consequently, they were better predictors for the non-PLTL group.

Table 2. The coefficients of both multiple regression and determination

\begin{tabular}{|c|c|c|c|c|c|c|}
\hline \multicolumn{3}{|c|}{ PLTL group } & \multicolumn{3}{c|}{ NON-PLTL group } \\
\hline Model & R & $\begin{array}{c}\text { R } \\
\text { Square }\end{array}$ & $\begin{array}{c}\text { Adjusted R } \\
\text { Square }\end{array}$ & R & R Square & $\begin{array}{c}\text { Adjusted R } \\
\text { Square }\end{array}$ \\
\hline 1 & .315 & .099 & .072 & .380 & .144 & .114 \\
\hline
\end{tabular}

Model 1. Predictors: (Constant), state and test anxiety

To assess the statistical significance of the result, it was necessary to look in Table 3 below. The combination of the predictor (state and test anxiety) was significantly related to general chemistry grade, $\mathrm{F}(2,65)=3.59, \mathrm{p}=.033$ for PLTL, $\mathrm{F}(2,57)=4.81, \mathrm{p}=.012$ for the non-PLTL group. Therefore, state and test anxiety can be used to predict the GC grade of engineering students in both groups. 
Table 3. ANOVA results

\begin{tabular}{|c|c|c|c|c|c|c|c|c|c|c|c|}
\hline \multirow[b]{2}{*}{$\frac{\bar{g}}{2}$} & & \multicolumn{5}{|c|}{ PLTL group } & \multicolumn{5}{|c|}{ NON-PLTL group } \\
\hline & & SS & df & MS & $\mathbf{F}$ & Sig. & SS & df & MS & $\mathbf{F}$ & Sig. \\
\hline \multirow{3}{*}{1} & Regression & 1160.54 & 2 & 580.27 & 3.59 & .033 & 1879.05 & 2 & 939.52 & 4.81 & .012 \\
\hline & Residual & 10505.89 & 65 & 161.63 & & & 11133.84 & 57 & 195.33 & & \\
\hline & Total & 11666.43 & 67 & & & & 13012.88 & 59 & & & \\
\hline
\end{tabular}

Note: Model 1. Predictors: (Constant), state and test anxiety.

SS: Sum of Squares, MS: Mean Square

Additionally, the regression equations were written with the B value in Table 4 . Equation 1 could be used to predict the total grade of PLTL students while equation 2 could be used to predict the total grade of non-PLTL students

$$
\begin{aligned}
& Y(\text { total grade })=80,93 X-0,017(\text { state anxiety })-0,333(\text { test anxiety }) \\
& Y(\text { total grade })=86,28 X-0,212(\text { state anxiety })-0,324(\text { test anxiety })
\end{aligned}
$$

\subsection{Addressing the second research question: Determination of the best predictor}

For the comparison of the contribution of each anxiety variable, beta values in Table 4 were used. The largest beta coefficient belonged to test anxiety whose beta values were -.307 for PLTL and -.260 for non-PLTL groups. This meant that this variable made the strongest unique contribution to explaining the general chemistry grade when the variance explained by all other variables in the model was controlled for. Besides, the beta value for state anxiety was lower compared to test anxiety, indicating that it made less of a unique contribution.

Table 4. Coefficients for each of the predictors

\begin{tabular}{|c|c|c|c|c|c|c|c|c|}
\hline \multirow{4}{*}{ Group } & Model & \multirow{2}{*}{ B } & \multirow{2}{*}{ Beta } & \multirow{2}{*}{ Sig } & $\begin{array}{c}\text { Zero- } \\
\text { order }\end{array}$ & Partial & Part & $\begin{array}{c}\text { Part } \\
\text { square }\end{array}$ \\
\hline \multirow{3}{*}{ PLTL } & (Constant) & 80.93 & & .000 & & & & \\
\cline { 3 - 9 } & State anxiety & -.017 & -.017 & .902 & -.168 & -.015 & -.015 & .000225 \\
\cline { 2 - 9 } & Test anxiety & -.333 & -.307 & .027 & -.315 & -.271 & -.267 & .0713 \\
\hline \multirow{2}{*}{$\begin{array}{c}\text { Non- } \\
\text { PLTL }\end{array}$} & ClConstant) & 86.28 & -.260 & .000 & & & & \\
\cline { 2 - 9 } & State anxiety & -.212 & -.165 & .273 & -.314 & -.145 & -.136 & .0184 \\
\hline
\end{tabular}

When the sig value was examined, for PLTL group test anxiety made a statistically significant unique contribution to the prediction of total score $(\mathrm{p}=0.027)$; however, state anxiety did not make any unique contribution. In addition, for the non-PLTL group, although the combination of state and test anxiety has a statistical significance to predict their GC grade. Statistically, insignificance in the results may be due to the overlap between independent variables in the model since the shared variance was excluded from the results. According to Pallant [6], this is very dependent on which variables are included in the equation and how much overlap there is among them. 
The part correlation coefficient in Table 4 referred to the semi-partial correlations coefficients. The square of this value was the indication of the contribution of that variable to the total $\mathrm{R}$ square. Test anxiety had a unique contribution of 7.13 percent to the explanation of variance in GC grade of PLTL students. $4.67 \%$ of total variance in general chemistry grade of non-PLTL students is uniquely explained by test anxiety while $1.84 \%$ of total variance in general chemistry grade of non-PLTL students is uniquely explained by state anxiety.

Accordingly, since test anxiety had a significant unique contribution, it could be used to predict the GC grade of PLTL students. It was also possible to predict that PLTL students having a high level of test anxiety tend to get low GC grade.

\subsection{Addressing the third research question: Control for the possible effect of trait anxiety}

Table 5. Model summary for predicting general chemistry grade after controlling trait anxiety

\begin{tabular}{|c|c|c|c|c|c|c|c|c|}
\hline \multirow[t]{2}{*}{ Group } & \multirow[t]{2}{*}{ Model } & \multirow[t]{2}{*}{$\mathbf{R}$} & \multirow{2}{*}{$\begin{array}{c}\text { R } \\
\text { Square }\end{array}$} & \multirow{2}{*}{$\begin{array}{c}\text { R Square } \\
\text { Change }\end{array}$} & \multicolumn{4}{|c|}{ Change Statistics } \\
\hline & & & & & $\begin{array}{c}\text { F } \\
\text { Change }\end{array}$ & df1 & df2 & $\begin{array}{c}\text { Sig. F } \\
\text { Change }\end{array}$ \\
\hline \multirow[t]{2}{*}{ PLTL } & 1 & .159 & .025 & .025 & 1.710 & 1 & 66 & .195 \\
\hline & 2 & .323 & .104 & .079 & 2.829 & 2 & 64 & .066 \\
\hline \multirow{2}{*}{$\begin{array}{l}\text { Non- } \\
\text { PLTL }\end{array}$} & 1 & .270 & .073 & .073 & 4.575 & 1 & 58 & .037 \\
\hline & 2 & .387 & .149 & .076 & 2.513 & 2 & 56 & .090 \\
\hline
\end{tabular}

Note: Model 1. Predictors: (Constant), trait anxiety

Model 2. Predictors: (Constant), trait, state, and test anxiety

After trait anxiety was entered, model 1 (takes unique contr. plus shared variance) explained $2.5 \%$ of the variance and after both state anxiety and test anxiety were entered the overall model 2 explained $10.4 \%$ of the variance. Moreover, after the effect of trait anxiety was removed, state and test anxiety explained an additional $7.9 \%$ of the variance in general chemistry grade of PLTL group, R square change $=.079$, F change $(2,64)=2,829$, $\mathrm{p}>0.05$. Similarly, state and test anxiety explained an additional $7.6 \%$ of the variance in general chemistry grade of the non-PLTL group after the effect of trait anxiety was removed, $\mathrm{R}$ square change $=.076, \mathrm{~F}$ change $(2,56)=2,513, \mathrm{p}>0.05$. However, those were not a significant contribution, as indicated by the Sig. F change in Table 5. This can be due to the presence of a high correlation between them.

Table 6. ANOVA results of two models for both PLTL and non-PLTL group

\begin{tabular}{|c|c|c|c|c|c|c|c|c|c|c|c|}
\hline & & \multicolumn{5}{|c|}{ PLTL group } & \multicolumn{5}{|c|}{ NON-PLTL group } \\
\hline$\frac{\bar{\Phi}}{\bar{c}}$ & & SS & df & MS & F & Sig. & SS & df & MS & $\mathbf{F}$ & Sig. \\
\hline \multirow{3}{*}{1} & Regression & 294.68 & 1 & 294.68 & 1.71 & .195 & 951.32 & 1 & 951.33 & 4.58 & .037 \\
\hline & Residual & 11371.75 & 66 & 172.30 & & & 12061.57 & 58 & 207.96 & & \\
\hline & Total & 11666.43 & 67 & & & & 13012.88 & 59 & & & \\
\hline \multirow{3}{*}{2} & Regression & 1218.46 & 3 & 406.15 & 2.49 & .068 & 1944.55 & 3 & 648.18 & 3.28 & .027 \\
\hline & Residual & 10447.97 & 64 & 163.25 & & & 11068.34 & 56 & 197.65 & & \\
\hline & Total & 11666.43 & 67 & & & & 13012.88 & 59 & & & \\
\hline
\end{tabular}

Note: Model 1. Predictors: (Constant), trait anxiety

Model 2. Predictors: (Constant), trait, state, and test anxiety

SS: Sum of Squares, MS: Mean Square 
The ANOVA table indicated that the model as a whole was not statistically significant for PLTL group $(\mathrm{F}(3,64)=2,49, \mathrm{p}=0.068)$ while it was statistically significant for the nonPLTL group $(\mathrm{F}(3,56)=3,28, \mathrm{p}=0.027)$.

Table 7. Coefficients of predictors for model 1 and 2

\begin{tabular}{|c|c|c|c|c|c|c|c|}
\hline \multirow{2}{*}{ Model } & \multirow{2}{*}{ Predictors } & \multicolumn{3}{|c|}{ PLTL group } & \multicolumn{3}{c|}{ NON-PLTL group } \\
\cline { 3 - 8 } & & B & Beta & Sig. & B & Beta & Sig. \\
\hline \multirow{3}{*}{1} & Constant) & 73.34 & & .000 & 78.54 & & .000 \\
\cline { 2 - 8 } & Trait anxiety & -.176 & -.159 & .195 & -.362 & -.270 & .037 \\
\hline \multirow{4}{*}{2} & Constant) & 80.25 & & .000 & 85.43 & & .000 \\
\cline { 2 - 8 } & Trait anxiety & .134 & .121 & .554 & .171 & .127 & .567 \\
\cline { 2 - 8 } & State anxiety & -.095 & -.092 & .622 & -.300 & -.233 & .227 \\
\cline { 2 - 8 } & Test anxiety & -.373 & -.344 & .025 & -.387 & -.311 & .080 \\
\hline
\end{tabular}

Note: Model 1. Predictors: (Constant), trait anxiety

Model 2. Predictors: (Constant), trait, state, and test anxiety

To find out how well each of the variables contributes to the final equation, we need to look in model 2 row in Table 7. Scanning the sig. column, there was only one variable that made a unique statistically significant contribution in the final model with a higher beta value (beta $=-.344, p=0.025$ ) that represented the unique contribution of test anxiety when the overlapping effects of all other variables were statistically removed.

\section{Conclusion}

Consequently, test anxiety can be used to predict the general chemistry grade of PLTL students. Due to significant negative correlation $(r=-.315)$, low test-anxious students in PLTL are likely to succeed in or get higher grades in general chemistry. Implementing innovative and effective teaching methods such as PLTL may not be sufficient to increase student understanding and enhance their performance if they have especially high anxiety. At the beginning of the semester, the instructor can use a diagnostic test to measure the test anxiety of the students as well as suggest some strategies that high test anxious students may use.

\section{References}

1. J. Osborne, S. Simon, S. Collins, Attitudes towards science: A review of the literature and its implications, Int. J. Sci. Educ., 25, 1049-1079 (2003).

2. C. D. Spielberger, R. L. Gorsuch, R. Lushene, P. R. Vagg, G. A. Jacobs, Manual for the state-trait anxiety inventory (Form Y), Palo Alto, CA: Consulting Psychologists Press (1983).

3. D. D. Szafranski, T. L. Barrera, P. J. Norton, Test anxiety inventory: 30 years later. Anxiety, Stress, \& Coping, 25, 667-677 (2012).

4. L. Gafney, P. Varma-Nelson, Innovations in science education and technology: Vol. 16. Peer-led team learning: Evaluation, dissemination, and institutionalization of a college level initiative. Weston, MA: Springer (2008).

5. J. R. Fraenkel, N. E. Wallen, H. H. Hyun, How to design and evaluate research in education (8th ed.). New York: McGraw-Hill (2012).

6. J. Pallant, SPSS survival manual: A step by step guide to data analysis using the SPSS program, 4th Edition, Allen \& Unwin, Berkshire (2011) 